\title{
Effective Decontamination and Remediation After Elemental Mercury Exposure: A Case Report in the United States
}

\author{
Kelly Johnson-Arbor ${ }^{1,2}$, Brian Schultz ${ }^{2}$ \\ ${ }^{1}$ Department of Plastic and Reconstructive Surgery, MedStar Georgetown University Hospital, Washington, DC, USA; ${ }^{2}$ National Capital Poison \\ Center, Washington, DC, USA
}

Elemental mercury exposure can result in significant toxicity. Source decontamination and remediation are often required after larger elemental mercury exposures, but the details of these processes are infrequently reported. In the case described herein, a 64-year-old woman and her husband were exposed to elemental mercury in their home after the husband purchased it online for the purpose of recreational barometer calibration. After the mercury reportedly spilled during the calibration process, a vacuum cleaner was used to decontaminate the affected surface; this led to extensive mercury contamination of the home. The couple was relocated from the home while remediation occurred over the course of several weeks. Vacuum cleaning of an elemental mercury spill can lead to extensive volatilization and recirculation of mercury vapor. For smaller mercury spills, careful removal of visible mercury beads by using an eyedropper, cardboard, and masking tape is recommended. Larger spills require professional decontamination and remediation and may necessitate involvement of governmental resources. Vacuum cleaning should not be used as an initial method of decontamination after elemental mercury exposure. Careful attention to source decontamination can reduce the emotional and financial costs associated with extensive remediation after elemental mercury exposure.

Key words: Mercury, Poisoning, Environment, Vacuum, Decontamination

\section{INTRODUCTION}

Elemental mercury is one of few metals that exist in a liquid state at or near room temperature [1]. Due to the significant morbidity associated with elemental mercury exposures, it is necessary to limit unintentional exposures to this toxin. The clinical characteristics of elemental mercury intoxication are

Received: June 19, 2021 Accepted: August 3, 2021

Corresponding author: Kelly Johnson-Arbor

Department of Plastic and Reconstructive Surgery, MedStar Georgetown University Hospital, 3800 Reservoir Road, NW, Washington, DC 20007, USA

E-mail: kkja@me.com

This is an Open Access article distributed under the terms of the Creative Commons Attribution Non-Commercial License (https://creativecommons.org/licenses/by$\mathrm{nc} / 4.0 /$ ) which permits unrestricted non-commercial use, distribution, and reproduction in any medium, provided the original work is properly cited. well described in the medical literature, but the details of appropriate decontamination and remediation of mercury-exposed settings are less frequently reported. This report describes a case of residential elementary mercury exposure, with an emphasis on aspects of decontamination and remediation.

\section{CASE REPORT}

A 64-year-old woman underwent a urine mercury assay ordered by her primary care physician (PCP). The result of this test, which was ordered for unknown reasons, was markedly elevated ( $216 \mu \mathrm{g} / \mathrm{g}$ creatinine, range $<4 \mu \mathrm{g} / \mathrm{g}$ creatinine). The result was not reported to the local health department or addressed in the patient's medical records until 3 years later, when her new PCP reviewed the result and ordered a repeat 24-hour urine assay. This test result was also abnormal $(30 \mu \mathrm{g} / \mathrm{L}$, range 
$<20 \mu \mathrm{g} / \mathrm{L}$ ), and the patient was referred to an outpatient medical toxicology clinic for further evaluation.

Upon toxicology clinic evaluation, the patient denied having symptoms of mercury toxicity including tremors, myalgias, paresthesias, or weakness. The physical examination was unremarkable. Laboratory testing was significant for proteinuria.

The patient was a retired human resources specialist. Her hobbies included reading and exercising, although she stated that she had not recently left her home for significant periods of time due to the severe acute respiratory syndrome coronavirus 2 (COVID-19) pandemic. She reported that her husband, a retired naval engineer, was the likely source of her mercury exposure, as he had a hobby of repairing barometers in the basement of their home. The patient's husband was also evaluated in the medical toxicology clinic after he was discovered to have a 24-hour urine mercury concentration of $22 \mu \mathrm{g} / \mathrm{L}$. He reported that he had purchased elemental mercury from an online source on multiple occasions and had the mercury mailed to their home. The element arrived at their home packaged in a glass vial; he poured it into glass barometers to calibrate them, using different workstations in the basement of the home. He had spilled elemental mercury on occasion on the unfinished concrete basement floor and had attempted to clean it up using a traditional vacuum cleaner as well as a shop vacuum.

Upon discovery of this information, the local health department was contacted, and a hazardous materials response team was dispatched to the residence for mercury vapor assessment. Elevated mercury vapor concentrations were detected throughout the home, with the highest levels noted in the basement. The couple was evacuated from their home and placed in temporary housing. Chelation with dimercaptosuccinic acid was prescribed for both patients.
A private company performed mercury remediation of the home. Many items in the home were confiscated and destroyed due to mercury contamination, including the couple's wedding attire, former military uniforms, and basement furniture. After several weeks of remediation, the home was declared safe for occupancy, and the couple moved back in. Follow-up 24-hour urine testing revealed decreasing mercury concentrations, although proteinuria persisted for several months after the conclusion of remediation.

\section{Ethics Statement}

Written consent for publication was obtained from the patients described in this report. Institutional review board approval was not required for publication of this case report.

\section{DISCUSSION}

This case report illustrates several challenges and concerns related to elemental mercury exposures in residential settings, including an uncommon exposure source, inadequate home decontamination, a delayed or unrecognized diagnosis, and the availability of elemental mercury from online purveyors.

Elemental mercury is 13.5 times as dense as water; small volumes of mercury can contain large amounts of the element and represent a health hazard to humans and animals [2]. Common sources of exposure to elemental mercury include thermometers, older sphygmomanometers, and regulating devices [3]. While barometers are well recognized as sources of elemental mercury, mercury toxicity from barometers is infrequently reported [4-6]. Barometers can contain from 5 ounces to 6 pounds of elemental mercury, making these devices potentially significant mercury exposure sources [7].

When spilled, elemental mercury forms small beads that

Table 1. Potential remediation methods for elemental mercury spills

\begin{tabular}{ll}
\hline Remediation method & \multicolumn{1}{c}{ Details/Limitations } \\
\hline Vacuuming & Enhances mercury vaporization \\
& Results in contamination of vacuum motor housing, even if the collector bag is changed \\
& Not recommended \\
Manual cleanup (use of cardboard, eyedropper, masking tape) & Can be used for small spills (less than $0.05 \mathrm{~mL}$ ) \\
Ventilation & $\begin{array}{l}\text { Includes turning thermostats to low settings to reduce the risk of additional heat-induced } \\
\text { vaporization }\end{array}$ \\
Sulfur/sulfide compounds & $\begin{array}{l}\text { Stabilize and immobilize mercury compounds } \\
\text { Selenium-containing shampoos can be used for hair and body decontamination }\end{array}$ \\
& $\begin{array}{l}\text { Powdered sulfur can be used to absorb mercury } \\
\text { Professional remediation }\end{array}$ \\
\hline
\end{tabular}


penetrate easily into porous surfaces and pose significant challenges in terms of surface decontamination and remediation. Potential residential remediation methods are presented in Table 1. Vacuuming is often performed as an initial decontamination measure; however, this practice is unsafe and highly discouraged, as vacuuming enhances the vaporization of elemental mercury. Additionally, vacuuming of elemental mercury leads to contamination of the vacuum motor housing, even if the collector bag on the vacuum cleaner is emptied or changed; this can result in recirculation of mercury vapor and ongoing contamination after vacuum reuse [8]. Unfortunately, the hazards associated with vacuum decontamination of residential mercury spills remain poorly understood. In a survey of both laypersons and medical personnel, 17 out of 70 respondents indicated that they would use a vacuum cleaner to cleanup after a residential mercury spill [9]. In the case described here, vacuuming of elemental mercury likely resulted in increased contamination of the patients' residence, leading to a prolonged remediation process.

After an elemental mercury spill, effective cleanup can limit the extent of the remediation process. Small mercury spills (generally described as less than or equal to the amount of mercury in a fever thermometer, or $0.05 \mathrm{~mL}$ ) on non-porous surfaces can be cleaned by individuals through use of cardboard, an eyedropper, or masking tape [2]. Thorough ventilation of the area should be performed, and vacuuming should be avoided for several weeks [10]. As heat also enhances elemental mercury volatilization, thermostats should be turned to low settings in areas where spills have occurred. Individuals should avoid walking through areas contaminated with elemental mercury, as cross-contamination of other areas may occur due to the presence of mercury beads on shoe soles. Sulfur and sulfide compounds stabilize and immobilize mercury, reducing the potential for toxicity [11]. Use of selenium sulfide-containing shampoos can be used for dermal decontamination of exposed individuals and pets [4]. Commercially available powdered sulfur can also be used to absorb elemental mercury after a spill [2].

Larger mercury spills necessitate comprehensive evaluation and often require specialized and professional remediation. In the United States, the Environmental Protection Agency's National Response Center is available 24 hours a day to assist in the evaluation of mercury spills involving more than 2 tablespoons [12]. Remediation of large mercury spills is an expensive endeavor; in the case described above, the costs of reme- diation alone (not including personal property losses) exceeded US\$200 000. Fortunately, and as happened in this case, homeowner insurance policies often cover the costs associated with residential remediation efforts. The high costs associated with mercury remediation, in addition to the expenses and inconvenience resulting from the relocation of affected individuals during this process, substantiate the need for increased knowledge about the use of appropriate decontamination processes after elemental mercury exposure.

It is unfortunate that the female patient in this case had an abnormally elevated urine mercury concentration that was not addressed by her PCP for 3 years. Although the patient's reported history and hazardous materials response team findings strongly suggest that barometer filling was the cause of the elevated urinary mercury concentrations in the patient and her husband, the lengthy delay between the initial laboratory finding and the detection of mercury in the home raises the question of whether another source of elemental mercury could have contributed to the initial urine assay result. While the identification of the initial exposure source may have been affected by recall bias, it is reassuring that both patients' urine mercury concentrations decreased after the remediation of their home was completed.

The male patient in this case reported that he purchased his elemental mercury from an online retailer. In the United States, elemental mercury can easily be purchased online, often from science-themed vendors, with few restrictions on its sale and transport. A review of Internet mercury retailers reveals that one company's website notes that mercury is "perfectly safe" to use in a classroom setting, whereas another retailer provides a link for powdered sulfur for the treatment of "small mercury spills". While the use of mercury is banned in some countries outside of the United States, the element can be easily obtained illegally through Internet purveyors [13]. An analysis of an Internet-based auction website found that toxic products, including mercury, were available for purchase from private retailers, often in packaging that was not child-resistant [14]. The easy availability of elemental mercury from online sources is concerning, as individuals who purchase mercury online may be unfamiliar with the recommended precautions for safe use and cleanup of this product.

In conclusion, elemental mercury spills can result in extensive contamination, necessitating prolonged and expensive remediation. Use of safe decontamination processes, including avoidance of vacuum cleaner use, use of thorough ventila- 
tion, and enhanced attention to prevention of cross-contamination, can limit ongoing exposure and reduce the need for extensive remediation after elemental mercury exposure. Both laypersons and medical professionals should be aware of the techniques involved in the cleanup of elemental mercury spills, to limit unnecessary exposures and reduce the emotional and financial costs of remediation.

\section{CONFLICT OF INTEREST}

The authors have no conflicts of interest associated with the material presented in this paper.

\section{FUNDING}

None.

\section{ACKNOWLEDGEMENTS}

None.

\section{AUTHOR CONTRIBUTIONS}

Conceptualization: KJA, BS. Funding acquisition: None. Writing - original draft: KJA. Writing - review \& editing: KJA, BS.

\section{ORCID}

$\begin{array}{ll}\text { Kelly Johnson-Arbor } & \text { https://orcid.org/0000-0001-7685-1942 } \\ \text { Brian Schultz } & \text { https://orcid.org/0000-0002-8736-9112 }\end{array}$

\section{REFERENCES}

1. Bo G, Ren L, Xu X, Du Y, Dou S. Recent progress on liquid metals and their applications. Adv Phys X 2018;3(1):1446359.

2. Caravati EM, Erdman AR, Christianson G, Nelson LS, Woolf AD, Booze LL, et al. Elemental mercury exposure: an evidence-based consensus guideline for out-of-hospital management. Clin
Toxicol (Phila) 2008;46(1):1-21.

3. Risher JF, Nickle RA, Amler SN. Elemental mercury poisoning in occupational and residential settings. Int J Hyg Environ Health 2003;206(4-5):371-379.

4. Scheepers PT, van Ballegooij-Gevers M, Jans H. Biological monitoring involving children exposed to mercury from a barometer in a private residence. Toxicol Lett 2014;231(3):365-373.

5. Oh CK, Jo JH, Jang HS, Kim MB, Kwon YW, Kwon KS. An unusual case of mercurial baboon syndrome from metallic mercury in a broken industrial barometer. Contact Dermatitis 2003; 49(6):309-310.

6. Koyun M, Akman S, Güven AG. Mercury intoxication resulting from school barometers in three unrelated adolescents. Eur J Pediatr 2004;163(3):131-134.

7. Centers for Disease Control and Prevention (CDC). Elemental mercury releases attributed to antiques--New York, 2000-2006. MMWR Morb Mortal Wkly Rep 2007;56(23):576-579.

8. Massachusetts Department of Public Health. Mercury and the hazards of vacuum cleaning. N Engl J Med 1975;292(7):369.

9. Zelman M, Camfield P, Moss M, Camfield C, Sweet L. Toxicity from vacuumed mercury: a household hazard. Clin Pediatr (Phila) 1991;30(2):121-123.

10. Baughman TA. Elemental mercury spills. Environ Health Perspect 2006;114(2):147-152.

11. Wang J, Feng X, Anderson CW, Xing Y, Shang L. Remediation of mercury contaminated sites - a review. J Hazard Mater 2012; 221-222:1-18.

12. United States Environmental Protection Agency. What to do if you spill more mercury than the amount in a thermometer [cited 2021 Jun 5]. Available from: https://www.epa.gov/mercury/what-do-if-you-spill-more-mercury-amount-thermometer.

13. Joy A, Qureshi A. Mercury in dental amalgam, online retail, and the Minamata convention on mercury. Environ Sci Technol 2020;54(22):14139-14142.

14. Blok D, Ambrose L, Ouellette L, Seif E, Riley B, Judge B, et al. Selling poison by the bottle: availability of dangerous substances found on eBay ${ }^{\oplus}$. Am J Emerg Med 2020;38(4):846-848. 